\title{
STUDY OF DIMENSIONS OF FLOW STATE OF BADMINTON PLAYERS
}

\author{
Gurmeet Singh*, Neeraj Malik** \\ Dept. of Physical Education, Panjab University, \\ Chandigarh, India.
}

\begin{abstract}
This Study was conducted to know the present Flow State of the Indian Universities Badminton team which was going to participate in 26th Summer Universiade at Shenzen, China. And to know the relation between the flow and its dimensions based on the Flow State Scale -2 (Jackson \& Eklund, 2004). For this study both the boys and girls teams were selected which consists of six members each. It was a survey designed study and Flow State Scale-2 (Jackson \& Eklund, 2004) was used to gather data to calculate overall Flow and its dimensions. The information was gathered during the training camp before the team left for China. In both the teams the present flow state was at a significant level 4.23 (Girls) \& 4.17 (Boys) and Overall flow and other dimensions yielded a significant positive correlation, for girls team flow yielded a significant positive correlation Merging $(r=.76)$, Concentration $(r=.85)$, Time $(r=$ .89), Autotelic ( $r=.77)$. For boys team flow yielded a significant positive correlation Merging $(r=89)$, Goals $(r=.74)$, Control $(r=.82)$. So it can be concluded that both the teams are in a better Flow State when they left for the championship and above said dimensions are highly correlated with overall flow state of the players in both boys and girls.
\end{abstract}

Keywords: Flow, Badminton players, Badminton

As an optimal psychological state, flow represents those moments when everything comes together for the performer. Flow is often associated with high levels of performance and a very positive experience. Csikszentmihalyi (1975) developed the concept after investigating the experiences of diverse groups during times when everything came together during performance of one's chosen activity. These activities included surgery, dancing, chess, and rock climbing. Despite such diversity in settings, there was considerable consistency of responses regarding what was felt during moments that stood out as being special in some way for the performer.

Since his initial investigations where the term "flow" was chosen to denote these special absorbing experiences, Csikszentmihalyi (e.g., 1990, 1997) continues to examine the flow construct and how it is experienced. Flow has been examined in settings that range from daily living (Csikszentmihalyi, 1997) to major scientific discoveries (Csikszentmihalyi, 1996). Remarkable consistency has been found in the described flow experiences of individuals across diverse settings. Flow is regarded as a special psychological state, one that brings the recipient much enjoyment. Flow can occur at different levels of complexity, but by definition flow is intrinsically rewarding regardless of whether it involves a simple game of throw and catch or a complicated and dangerous gymnastics routine. Csikszentmihalyi (1975) referred to the different levels of flow experience as micro and macro flow. Micro flow experiences were postulated to fit the patterns of everyday life, whereas macro flow was reserved for experiences associated with higher levels of complexity and demand on the participant. Flow occurs when one is totally involved in the task at hand. When in flow, the performer feels strong and positive, not worried about self or of failure. Flow can be defined as an experience that stands out as being better than average in some way, where the individual is totally absorbed in what she or he is doing, and where the experience is very rewarding in and of itself.

The Flow State Scale-2 (FSS-2) and Dispositional Flow Scale-2 (DFS-2) are presented as two self- report instruments designed to assess flow experiences in physical activity. The FSS-2 and DFS-2 were designed to assess, respectively, flow experiences within a particular event and the dispositional tendency to experience flow in physical activity. These scales were theoretically grounded in Csikszentmihalyi's (1990) nine dimensional conceptualizations of flow. These nine dimensions are, challenge-skill balance, action-awareness merging, clear goals, unambiguous feedback, and concentration 
on task, sense of control, loss of self-consciousness, time transformation, and auto telic experience. Together, they represent the optimal psychological state of flow; singly, they signify conceptual elements of this state.

Nine flow dimensions

Challenge-skill balance. Challenges can be thought of as opportunities for actions, or goals. Skills are the capacities that we possess to produce desired outcomes. Critical to the challenge -skill balance is that the perception of challenge and skill drives the equation. This perception makes our beliefs or confidence regarding what we are able to do in a situation more important than what our objective skill levels might be. Further, challenges can be defined in a personal way, separate from any structures of an activity. It is the perception of the defined challenge that is critical to flow occurring.

Action-awareness merging. When people are asked to describe what it feels like to be in flow, ideas about action-awareness merging surface. As described by a cyclist in the following paragraph, the performer feels as though he or she is one with the activity being performed."It just doesn't seem like you're sitting on a bike. You feel like one piece of machinery working together . . . like you're part of this machine that you were born with, and it's how you move."How does this experience come about? Through total absorption in what you are doing. Such involvement can lead to a perception of oneness that brings harmony and peace to an active engagement with a task. Athletes often describe a sense of effortlessness and spontaneity associated with this flow dimension of action-awareness merging. Feelings of automaticity are described by athletes, whose well -learnt routines enable them to process subconsciously and pay full attention to their actions. The unity of consciousness apparent in this flow dimension illustrates the idea of growth in complexity that results from flow experiences.

Clear goals. Goal setting is a process that, when undertaken correctly, helps move a performer toward flow. Knowledge of objectives, performance preparation and planning, awareness, and understanding the fine details required for a successful outcome all help to set the stage for flow. Once in this state, individuals describe knowing clearly what it is they are supposed to do. When in flow, this clarity of purpose occurs on a moment- by-moment basis, keeping the performer fully connected to the task and responsive to appropriate cues.Sports provide an excellent setting for actions bound by clear goals and rules. The structure of preset action allows more attention to be focused on immediate tasks. Personal goals can also be set and continually monitored against this backdrop of inbuilt goals for action. In fact, it is vital that athletes plan for their performance so that, when the time comes, there is clarity of focus on the particular goals relevant to individual performers and performances. As a runner describes in the following paragraph, without such goal preparation, flow is unlikely:"If you stand up on the block and just expect it to happen, and haven't thought about what you want to think about, it won't happen."Goals are a necessary part of achieving something worthwhile in any endeavor. The focus that goals provide to actions also means that they are an integral component of the flow experience.

Unambiguous feedback. Hand-in-hand with clear goals comes the processing of how performance is progressing in relation to these goals. Paying attention to feedback is an important step in determining whether one is on track toward goals that have been set. When in flow, feedback is easier to receive. The performer receives clear, unambiguous information that he or she processes effortlessly, keeping performance heading in the right direction. When in flow, athletes speak of "knowing clearly what to do" and having "everything click/Teedback can come from many sources. For athletes, one of the most important sources of feedback is kin aesthetic awareness, or knowing the spatial location of one's body. This awareness is the internal information an athlete needs to optimize his or her movements. Recognizing how the quality of a performance relates to an ideal performance enables athletes to know, on a continuous basis, whether their movements are what they want them to be. Feedback can come from a range of external sources-from the environment in which the performance is occurring to the information provided by competitors or spectators. It is not necessary for feedback to always be positive for flow to occur or continue. When in flow, the nature of clear and immediate feedback means that adjustments can be made to either keep a performer in flow or enable the performer to achieve the state of flow. When receiving feedback associated with a flow state, the performer does not need to stop and 
reflect on how things are going. Moment by moment, information is seamlessly integrated into performance.

Total concentration on the task at hand. This fifth characteristic defines the flow state. When in flow, one is totally focused in the present on a specific task being performed. There are no extraneous thoughts, and the distractibility that often accompanies involvement on any task is wonderfully absent. Experiencing such clear moments provides much satisfaction, which in turn leads to the growth in complexity those results from flow experiences. Being totally connected to the task at hand epitomizes the flow state, and is one of its most, often, mentioned characteristics. This connectedness relies on a presentcentered focus. The past and the future are not roads to flow; flow resides in being able to be in the present moment an interesting aspect of the concentration experienced in flow is that even though it is complete and intense, this type of concentration is spontaneous. In contrast to usual experiences, no effort is required to keep the mind on task when in flow. In the following quote, an athlete illustrates this contrast."Well, it's a total focus. But it's a balance really, between a total focus and a total release in a way. Because you are totally focused ... on the other hand, it is also happening on its own. It is like it is a total automatic process. "

Sense of control. Another frequently mentioned flow characteristic is a feeling of being in control. One athlete described this feeling as an "unshatterable" self-esteem. Others have described a sense of infallibility when performing in flow. This empowered feeling frees one from the all-toofrequent fear of failure that creeps into performance. Failure thoughts are nowhere to be found during flow, enabling the individual to take on the challenges at hand. Control, like the challenge- skills relationship, is a delicately balanced component of flow. Although the perception of control is inherent to the experience, absolute situational control does not actually exist in an experiential sense. One must experience challenge to experience flow. Challenge does not exist under conditions of absolute control. Hence, the experience of total control most likely moves an individual away from the experience of flow and on to relaxation or boredom. The possibility of keeping things under control keeps flow active. Like flow itself, the sense of control usually lasts only a short time. This relates back to keeping at the cutting edge of the challenge-skills balance within a situation. If the feeling of being in control keeps going indefinitely, then the scales have tipped in favor of skills over challenge, and flow is lost.

Loss of self-consciousness. Most people live their lives surrounded by evaluations of how they are doing. Emanating from many sources, one of the most insistent is from the self. In situations of importance, it is difficult to stop constantly evaluating how we are doing in the eyes of others; however, this evaluation is necessary for flow. When an individual is no longer concerned with what others think of him or her, this individual has lost self-consciousness. Athletes often find it difficult to lose selfconsciousness. The very public nature of the activity affords many opportunities for evaluation. In any activity, we face criticism - both from others and ourselves - which turns attention away from the task and onto the self. The ego, that part of our self that questions, critiques, and prompts self-doubt, needs to be quieted for flow. We can think of flow as unselfconscious action. It is liberating to be free of the voice within our head that questions whether we are living up to the standards that we perceive are important to be met.

Transformation of time. Deep moments of flow seem to transform our perception of time. For some, the experience is that time stops. For others, time seems to slow. And still for others, time seems to pass more quickly than expected. These sensations come about through the intense involvement of a flow experience. Because nothing else is entering our awareness during flow, we may be surprised to find that significant time has passed while in the state of flow. The intensity of focus may also contribute to perceptions of time slowing, with a feeling of having all the time in the world to execute a move that is in reality very much time- limited. Thus, there seems to be a close link between depth of concentration and time transformation. )The latter dimension may be the one least frequently experienced. The lack of association between time transformation and the other flow dimensions in the sports research conducted to date is discussed in subsequent chapters. It may be that the nature of the sports activity, where time is often part of the infrastructure or part of the challenge, is not easily lost. Another possible explanation is 
that this dimension occurs only when the flow experience is very deep. There may be a fleeting perception of this dimension when it does occur. When this dimension is experienced, it is one of the liberating dimensions of flow, to feel free from the time dependence under which we live most of our lives.

Autotelic experience. Csikszentmihalyi (1990) coined the term auto telic experience to describe the intrinsically rewarding experience that flow brings to the individual. As described by Csikszentmihalyi, the word is derived from two Greek words that describe doing something for its own sake: auto $=$ self and telos $=$ goal. Flow is such an enjoyable experience that one is motivated to return this state. Once experienced, flow becomes a much sought after state. Csikszentmihalyi described this dimension as the end result of the other eight flow dimensions. Athletes endorse the enjoyment component of flow strongly, with descriptions like "such a rush," "exhilarating," and "a buzz." For many, flow is the defining motivation to keep pushing towards higher limits, as described by a cyclist in the following paragraph.'There is no experience in sports that is as exhilarating or rewarding as being in flow. That's what it is. That's what makes me keep riding - knowing that I might get it again."

\section{METHOD}

The study was a survey design; subjects were selected on purposive sampling method from the training camp of Indian Universities Badminton team which was going to participate in 26th Summer Universiade at Shenzen, China. The subjects were the members of both the girls and boys badminton teams which were selected to represent the Indian Universities in the 26th Summer Universiade at Shenzen, China. Total number of subjects was N-12 (girls - 6) (boys -6). The was motivated by the coach, the coaching staff was properly introduced about the study and its uses the coaching staff was briefed about the procedure of study and how it will be valuable for the team. The researcher introduced the flow state scale-2 to the subjects which was used to gather information for the study. Information was gathered at once from all the subjects and Flow State Scale-2 (FSS-2) (Jackson \& Eklund, 2004) was used for it, information was gathered on same day before the session in the presence of researcher and coaching staff. The flow scale manual (Jackson \& Eklund, 2004) referred for the procedure of collection of data and its analysis. In this study the data analysis was done by using a simple Pearson Correlation in SPSS, to

measure the relation between the flow and its dimensions with an alpha level of significance set at $\mathrm{p}<.05$ (1-tailed).

\section{RESULTS}

The results of the study show a significant positive correlation, for girls team flow yielded a significant positive correlation Merging $(\mathrm{r}=.76)$, Concentration $(\mathrm{r}=.85)$, Time $(\mathrm{r}=.89)$, Auto telic $(\mathrm{r}=$ .77). For boys team flow yielded a significant positive correlation Merging $(r=89)$, Goals $(r=.74)$, Control $(\mathrm{r}=.82)$. These results make it clear that there is relation between the flow state and its dimensions. 
Figure-1

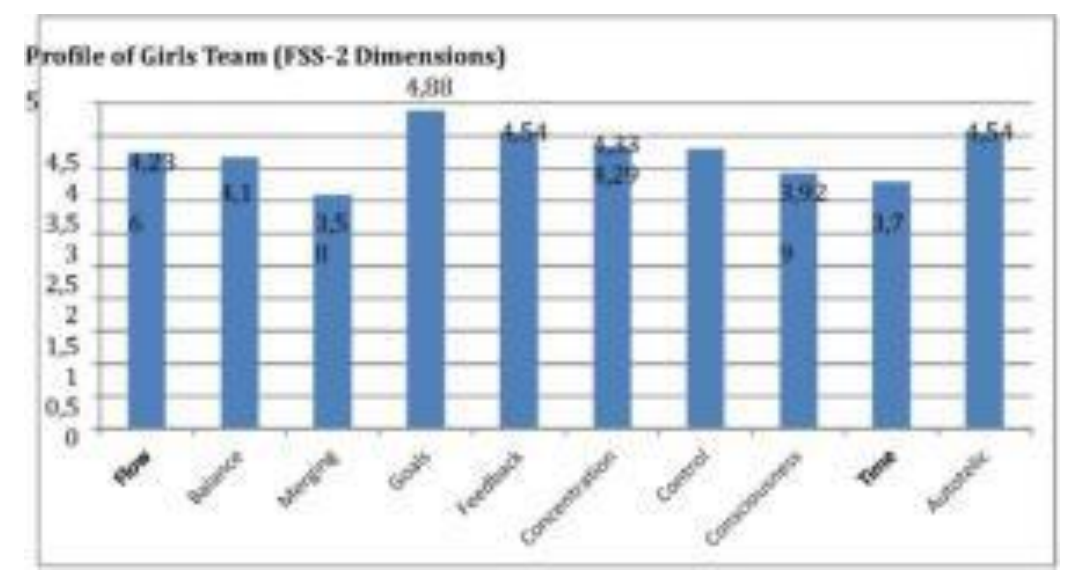

Figure-2
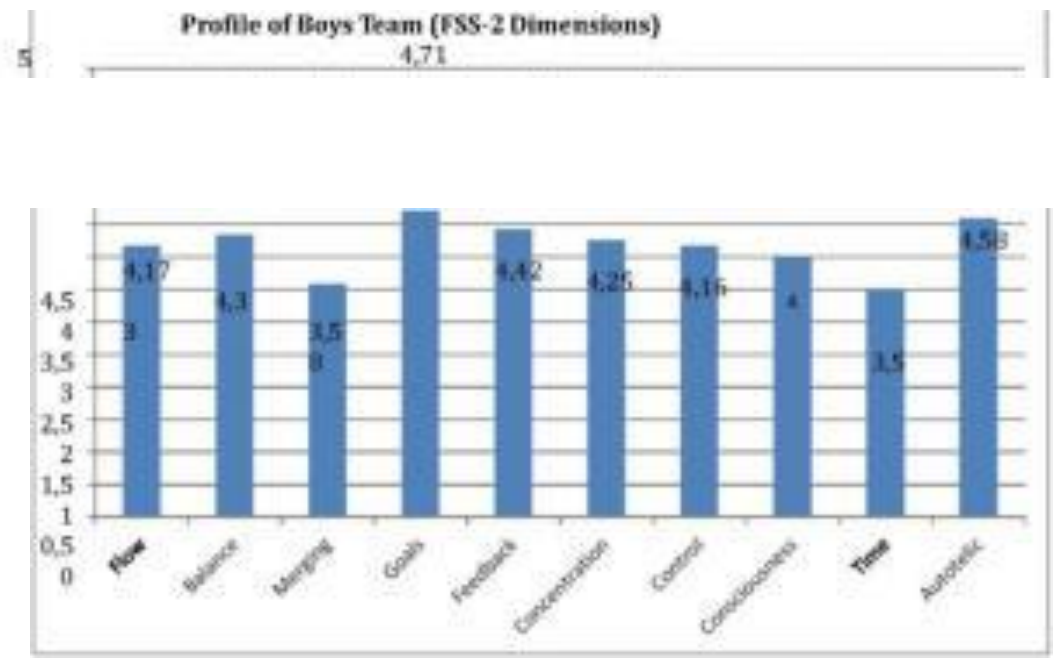

Figure-1 the flow and its dimensions are presented which are for the girl's team in this figure the complete picture of the girl's team is clear the flow state bar is at 4.23 which is good and it is clear that flow is at this good level because of its dimensions. In this figure- 2 the flow and its dimensions are presented which are for the boy's team in this figure the complete picture of the boy's team is clears the flow state bar is at 4.17 which is good but less than the girl's team and it is clear that flow is at this level because of its dimensions. 
Statistical Results of Girl's Team based on SPSS Table-1

\begin{tabular}{|c|c|c|c|}
\hline \multicolumn{4}{|c|}{ Descriptive Statistics girls Team } \\
\hline & Mean & Std. Deviation & N \\
\hline Flow & 4.2265 & .47567 & 6 \\
\hline Balance & 4.1667 & .84656 & 6 \\
\hline Merging & 3.5833 & .78528 & 6 \\
\hline Golals & 4.8750 & .30619 & 6 \\
\hline Feedback & 4.5417 & .90023 & $\mathbf{6}$ \\
\hline Concentration & 4.3333 & .49160 & $\mathbf{6}$ \\
\hline Control & 4.2917 & .74861 & $\mathbf{6}$ \\
\hline Consciousness & $\mathbf{3 . 9 1 6 7}$ & $\mathbf{1 . 3 8 4 4 4}$ & $\mathbf{6}$ \\
\hline Time & $\mathbf{3 . 7 9 1 7}$ & .67854 & $\mathbf{6}$ \\
\hline Autotelic & 4.5417 & .45871 & $\mathbf{6}$ \\
\hline
\end{tabular}

Table-2

\begin{tabular}{|c|c|c|c|c|c|c|c|c|c|c|c|}
\hline \multicolumn{12}{|c|}{ Correlations $^{\mathrm{a}}$} \\
\hline & & Flow & d-1 & d-2 & d-3 & d-4 & d-5 & d-6 & d-7 & d-8 & d- \\
\hline \multirow{2}{*}{ Flow } & $\begin{array}{r}\text { Pearson } \\
\text { Correlatio }\end{array}$ & 1 & & & & & & & & & \\
\hline & $\begin{array}{l}{ }^{\mathrm{Si}}{ }^{(1-}{ }^{(1-} \\
\text { tailed) }\end{array}$ & & & & & & & & & & \\
\hline \multirow{2}{*}{ d-1 } & $\begin{array}{r}\text { Pearson } \\
\text { Correlatio }\end{array}$ & .715 & 1 & & & & & & & & \\
\hline & $\begin{array}{l}\mathrm{Si}_{\mathrm{g} .}(1- \\
\text { tailed) }\end{array}$ & .055 & & & & & & & & & \\
\hline \multirow[b]{2}{*}{ d-2 } & $\begin{array}{r}\text { Pearson } \\
\text { Correlatio }\end{array}$ & $.761 *$ & .370 & 1 & & & & & & & \\
\hline & $\begin{array}{l}\mathrm{Si}^{\mathrm{Si} .}{ }^{(1-} \\
\text { tailed) }\end{array}$ & .040 & .235 & & & & & & & & \\
\hline \multirow{2}{*}{ d-3 } & $\begin{array}{c}\text { Pearson } \\
\text { Correlatio }\end{array}$ & .663 & .530 & .052 & 1 & & & & & & \\
\hline & $\begin{array}{l}{ }^{S i} \mathbf{g} \cdot{ }^{(1-} \\
\text { tailed })\end{array}$ & .076 & .139 & .461 & & & & & & & \\
\hline d-4 & $\begin{array}{c}\text { Pearson } \\
\text { Correlatio }\end{array}$ & .174 & .612 & .348 & -.249 & 1 & & & & & \\
\hline
\end{tabular}




\begin{tabular}{|c|c|c|c|c|c|c|c|c|c|c|}
\hline & $\begin{array}{l}\mathrm{Si}_{\text {g. }}\left({ }^{(1-}\right. \\
\text { tailed })\end{array}$ & .371 & .098 & .250 & .317 & & & & & \\
\hline \multirow{2}{*}{ d-5 } & $\begin{array}{r}\text { Pearson } \\
\text { Correlatio }\end{array}$ & $.853 *$ & $.771^{*}$ & .367 & $.830^{*}$ & $=047$ & 1 & & & \\
\hline & \begin{tabular}{|l|}
${ }^{\mathrm{Si}}{ }^{(1-}{ }^{(1-}$ \\
tailed)
\end{tabular} & .015 & .036 & .237 & .020 & .465 & & & & \\
\hline \multirow[b]{2}{*}{ d-6 } & $\begin{array}{r}\text { Pearson } \\
\text { Correlatio }\end{array}$ & .569 & .283 & .078 & $.845^{*}$ & .430 & $.804 *$ & 1 & & \\
\hline & $\begin{array}{l}\mathrm{Si}_{\text {g. }}\left(1-{ }^{-}\right. \\
\text {tailed) }\end{array}$ & .119 & .294 & .442 & .017 & .198 & .027 & & & \\
\hline \multirow{2}{*}{ d-7 } & $\begin{array}{r}\text { Pearson } \\
\text { Correlatio }\end{array}$ & .661 & .014 & .606 & .413 & .478 & .416 & .438 & 1 & \\
\hline & $\begin{array}{l}{ }^{\mathrm{Si}} \text { g. }{ }^{(1-} \\
\text { tailed) }\end{array}$ & .076 & .489 & .101 & .208 & .169 & .206 & $\mid 192$ & & \\
\hline \multirow{2}{*}{ d-8 } & $\begin{array}{r}\text { Pearson } \\
\text { Correlatio }\end{array}$ & .894* & .334 & $.766^{*}$ & .572 & .188 & .700 & .636 & * $883 *$ & 1 \\
\hline & $\begin{array}{l}\mathrm{Si}_{\mathrm{g} .}{ }^{(1-} \\
\text { tailed })\end{array}$ & .008 & .259 & .038 & .118 & .361 & .061 & .087 & .010 & \\
\hline \multirow{2}{*}{ d-9 } & $\begin{array}{r}\text { Pearson } \\
\text { Correlatio }\end{array}$ & $.769^{*}$ & $.815^{*}$ & .509 & .578 & .479 & .591 & .176 & .282 & 4751 \\
\hline & $\begin{array}{l}\mathrm{Si}_{\text {g. }}{ }^{(1-} \\
\text { tailed })\end{array}$ & .037 & .024 & .151 & .115 & .168 & .108 & .369 & .294 & .170 \\
\hline
\end{tabular}

$\stackrel{\mathrm{K}}{\text {. Correlation is significant at the } 0.01 \text { level (1-tailed). a. List wise } \mathrm{N}=6}$

d-1= Balance, $d-2=$ Merging, $d-3=$ Goals, $d-4=$ Feedback, $d-5=$ Concentration, $d-6=$ Control, $d-7=$ Consciousness, $d-8=$ Time, $d-9=$ Auto telic.

Statistical Results of Boy's Team based on SPSS Table-3

\begin{tabular}{|c|c|c|c|}
\hline \multicolumn{4}{|c|}{ Descriptive Statistics boys Team } \\
\hline & Mean & Std. Deviation & N \\
\hline Flow & 4.1710 & .33948 & $\mathbf{6}$ \\
\hline Balance & 4.3333 & .40825 & 6 \\
\hline Merging & $\mathbf{3 . 5 8 3 3}$ & .73598 & $\mathbf{6}$ \\
\hline Goals & 4.7083 & .29226 & 6 \\
\hline Feedback & 4.4167 & .58452 & $\mathbf{6}$ \\
\hline Concentration & 4.2500 & .52440 & $\mathbf{6}$ \\
\hline Control & 4.1667 & .70119 & $\mathbf{6}$ \\
\hline Consciousness & 4.0000 & .52440 & 6 \\
\hline Time & $\mathbf{3 . 5 0 0 0}$ & .86603 & 6 \\
\hline Auto telic & 4.5833 & .40825 & 6 \\
\hline
\end{tabular}


Table-4

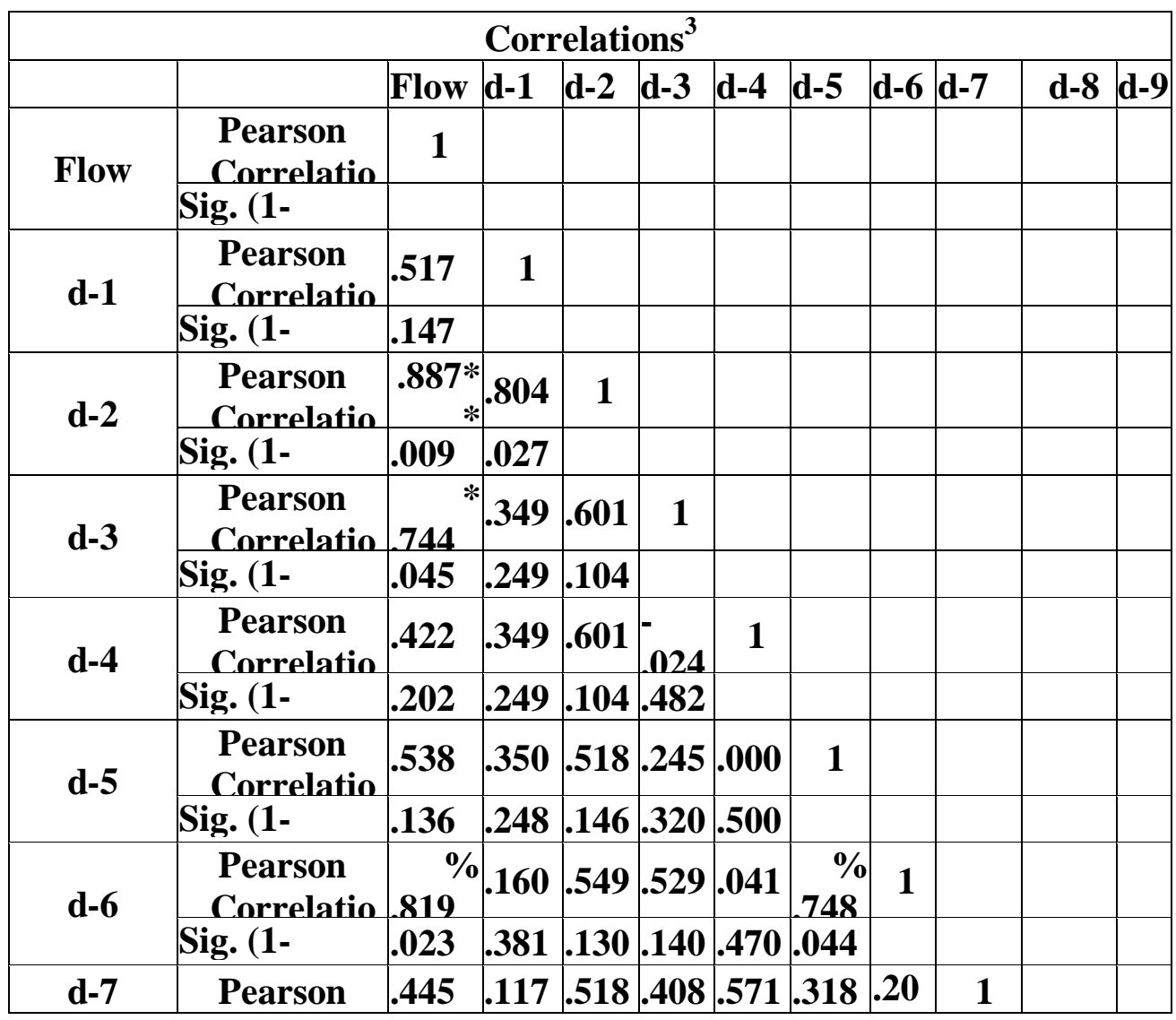

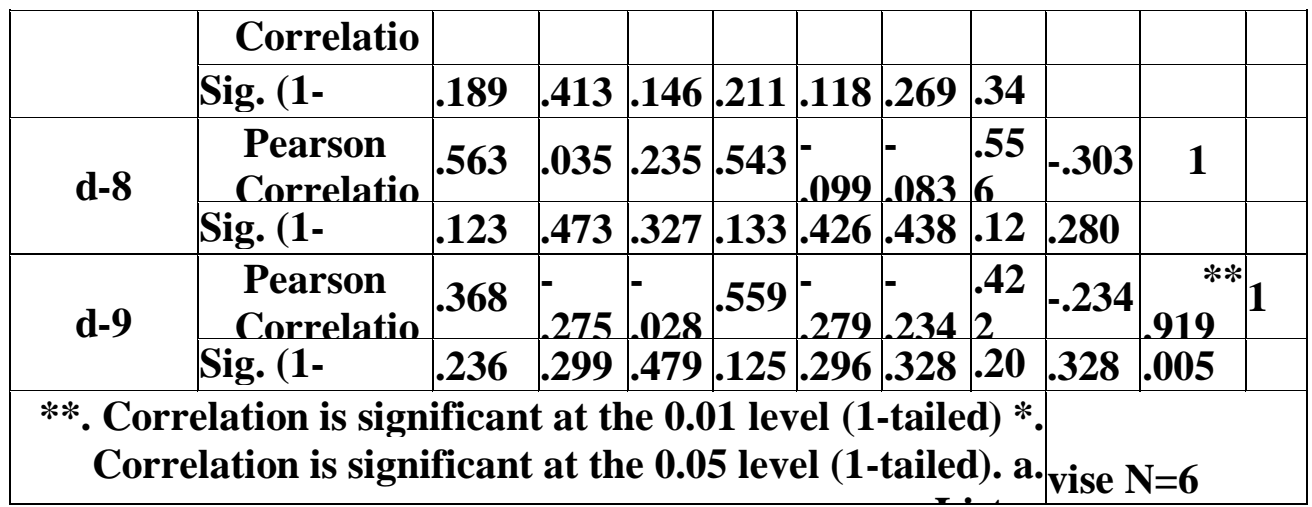

d-1= Balance, $\mathrm{d}-2=$ Merging, $\mathrm{d}-3=$ Goals, $\mathrm{d}-4=$ Feedback, $\mathrm{d}-5=$ - Concentration, $\mathrm{d}-$ $6=$ Control, $d-7=$ Consciousness, $d-8=$ Time, $d-9=$ Auto telic.

\section{DISCUSSION}

In this study the flow state of the players of Indian Universities Badminton team which was going to participate in 26th Summer Universiade at Shenzen, China was measured on the bases of Flow State Scale-2 (Jackson \& Eklund, 2004), and also measured the correlation between the flow and its dimensions based on the Flow State Scale-2 (Jackson \& Eklund, 2004). And after the calculations it was clear that the there is a positive and significant correlation between the flow and its dimensions. Csikszentmihalyi (1975) developed the concept after investigating the experiences of diverse groups during times when 
everything came together during performance of one's chosen activity. These activities included surgery, dancing, chess, and rock climbing. Despite such diversity in settings, there was considerable consistency of responses regarding what was felt during moments that stood out as being special in some way for the performer. The FSS-2 was theoretically grounded in Csikszentmihalyi's (1990) nine dimensional conceptualisations of flow. These nine dimensions are challenge-skill balance, action-awareness merging, clear goals, unambiguous feedback, and concentration on task, sense of control, loss of selfconsciousness, time transformation, and auto telic experience. Together, they represent the optimal psychological state of flow; singly, they signify conceptual elements of this state. Mugford A.L and Tennant L.K. (2005) also found significant relation between the social cohesion and flow state than with task cohesion. Indeed, 4 of the 9 sub dimensions were significant at .05 here also in this study 4 of 9

dimensions were significant at .05 in case of girl's team and 3 of 9 dimensions were significant at .05 in case of boy's team.

\section{CONCLUSION}

This study finds that there is a strong, positive relationship between the flow state and its dimensions based on Flow State Scale-2 (Jackson \& Eklund, 2004), and it also showed the present flow state of the Indian Universities Badminton team which was going to participate in 26th Summer Universiade at Shenzen, China.

\section{REFERENCES}

Jackson S. A \& Eklund R.C., (2004) The Flow Scale Manual, Printed by publisher graphics. Mugford A.L. \& Tennant L.K. (2005) Flow in a Team Sport Setting: Does Cohesion Matter Angus Mugford

Carron, A. V., Brawley, L. R., \& Widmeyer, W. N. (1998). The measurement of cohesiveness in sport groups. In J. L. Duda (Ed.), Advances in sport and exercise psychology measurement (pp. 213226). Morgantown, WV: Fitness Information Technology, Inc.

Carron, A. V., Brawley, L. N., \& Widmeyer, W. N. (2002). The Group Environment Questionnaire: Test Manual. Morgantown, WV: Fitness Information Technology, Inc.

Carron, A. V., Colman, M. M., Wheeler, L., \& Stevens, D. (2002). Cohesion and performance in sport: A meta-analysis. Journal of Sport \& Exercise Psychology, 24 (2), 168-188.

Jackson, S. A., \& Eklund, R. C. (2003). Assessing flow in physical activity: The Flow State Scale2 and Dispositional Flow Scale-2. Journal of Sport \& Exercise Psychology, 24 (2), 133-150.

Martin, J. J., \& Cutler, K. (2002). An exploratory study of flow and motivation in theater actors. Journal of Applied Sport Psychology, 14 (4), 344-352.

Terry, P. C., Carron, A. V., Pink, M. J., Lane, A. M., Jones, G. J. W., \& Hall, M. P. (2000). Perceptions of group cohesion and mood in sport teams. Group Dynamics: Theory, Research and Practice, 4 (3), 244-253.

Walker, J. T. (2002). Exploring the influence of the individual's ability to experience flow while participating in a group dependent activity on the individual's satisfaction with the group's performance. Unpublished doctoral dissertation, Clemson University. 